Review article

\title{
Tuberculosis-HIV Co-Infection: Progress and Challenges After Two Decades of Global Antiretroviral Treatment Roll-Out
}

\author{
Emilio Letang a,b,*, Jayne Ellis ${ }^{\mathrm{c}, \mathrm{d}}$, Kogieleum Naidoo e,f, Esther C. Casas ${ }^{\mathrm{g}}$, Paquita Sánchez ${ }^{\mathrm{b}}$, \\ Razia Hassan-Moosa ${ }^{\mathrm{e}, \mathrm{f}}$, Fiona Cresswell ${ }^{\mathrm{c}, \mathrm{h}, \mathrm{i}}$, Jose M. Miró ${ }^{\mathrm{j}}$, Alberto L. García-Basteiro ${ }^{\mathrm{a}, \mathrm{k}}$ \\ a ISGlobal, Hospital Clínic-Universitat de Barcelona, Barcelona, Spain \\ b Infectious Diseases Department, Hospital del Mar, Hospital del Mar Research Institute, Barcelona, Spain \\ ' Infectious Diseases Institute, College of Health Sciences, Makerere University, Kampala, Uganda \\ d Hospital for Tropical Diseases, University College London, London, UK \\ e Centre for the AIDS Programme of Research in South Africa (CAPRISA), Durban, South Africa \\ ${ }^{\mathrm{f}}$ MRC-CAPRISA HIV-TB Pathogenesis and Treatment Research Unit, Doris Duke Medical Research Institute, University of KwaZulu-Natal, South Africa \\ g Southern Africa Medical Unit, Médecins sans Frontières, Cape Town, South Africa \\ ${ }^{\mathrm{h}}$ Clinical Research Department, London School of Hygiene and Tropical Medicine, London, UK \\ ${ }^{\mathrm{i}}$ MRC-UVRI-London School of Hygiene and Tropical Medicine Uganda Research Unit, Entebbe, Uganda \\ j Infectious Diseases Service, Hospital Clínic-IDIBAPS, University of Barcelona, Barcelona, Spain \\ k Centro de Investigação em Saúde de Manhiça (CISM), Maputo, Mozambique
}

\section{A R T I C L E I N F O}

\section{Article history:}

Received 24 July 2019

Accepted 2 November 2019

Available online $\mathrm{xxx}$

\section{Keywords:}

Tuberculosis

HIV/AIDS

ART

Pathogenesis

Diagnosis

Treatment

Resource-limited settings

Implementation challenges

\begin{abstract}
A B S T R A C T
Despite wide antiretroviral scale-up during the past two decades resulting in declining new infections and mortality globally, HIV-associated tuberculosis remains as a major public health concern. Tuberculosis is the leading HIV-associated opportunistic infection and the main cause of death globally and, particularly, in resource-limited settings. Several challenges exist regarding diagnosis, global implementation of latent tuberculosis treatment, management of active tuberculosis, delivery of optimal patient-centered TB and HIV prevention and care in high burden countries. In this article we review the advances on pathogenesis, diagnosis, and treatment after nearly two decades of global roll-out of antiretroviral therapy and discuss the current challenges for the global control of tuberculosis-HIV co-infection.

(C) 2019 The Authors. Published by Elsevier España, S.L.U. on behalf of SEPAR. This is an open access article under the CC BY-NC-ND license (http://creativecommons.org/licenses/by-nc-nd/4.0/).
\end{abstract}

\section{Coinfección tuberculosis-VIH: avances y retos 2 décadas después de la implementación del tratamiento antirretroviral a nivel global}

\section{R E S U M E N}

A pesar de que el uso de antirretrovirales ha aumentado en uso y difusión durante las 2 últimas décadas, lo que ha resultado en la disminución de nuevas infecciones y de la mortalidad global, la tuberculosis asociada al VIH sigue siendo un importante problema de salud pública. La tuberculosis es la principal infección oportunista asociada al VIH y la principal causa de muerte a nivel mundial, particularmente en el marco de situaciones de recursos limitados. Existen varios retos con respecto al diagnóstico, la implementación global del tratamiento de la tuberculosis latente, el manejo de la tuberculosis activa, el proporcionar una prevención óptima de la tuberculosis y el VIH centrada en el paciente y la atención en países de alta carga. En este artículo revisamos los avances en la patogénesis, el diagnóstico y el tratamiento después de casi
Palabras clave:

VIH/SIDA

TARV

Patogénesis

Diagnóstico

Tratamiento

Situaciones de recursos limitados

Retos en implementación

\footnotetext{
* Corresponding author.

E-mail address: emili.letang@isglobal.org (E. Letang).
} org/licenses/by-nc-nd/4.0/). 
2 décadas de implementación global de la terapia antirretroviral y comentamos los retos actuales para el control global de la coinfección tuberculosis-VIH.

(C) 2019 Los Autores. Publicado por Elsevier España, S.L.U. en nombre de SEPAR. Este es un artículo Open Access bajo la licencia CC BY-NC-ND (http://creativecommons.org/licenses/by-nc-nd/4.0/).

\section{Introduction}

Worldwide, tuberculosis (TB) is the leading cause of death from a single pathogen. According to the World Health Organization (WHO), about 10 million developed active tuberculosis disease and 1.6 million people died in 2017. ${ }^{1}$ Globally, HIV-associated TB was estimated to be responsible for about $9 \%$ of all new cases and $20 \%$ of all TB-deaths. ${ }^{1}$ Encouragingly, the prevalence of HIV among new TB cases is slowly decreasing in recent years. Nevertheless, it is still unacceptably high in sub-Saharan Africa due to several challenges. ${ }^{1}$ Seventy-two per cent of all TB cases among people living with HIV (PLHIV) occurred in Africa (Fig. 1). The global burden of disease study estimates a slightly lower number of TB cases and less TBdeaths, especially among PLHIV, ${ }^{2}$ reflecting under-diagnosis and under-reporting of TB, a major obstacle to estimate the true number of new cases. Indeed, of the 920,000 HIV-associated TB cases estimated last year by the WHO, only $51 \%$ had been diagnosed and/or reported. Reducing this diagnostic gap is a priority of the global End TB strategy. ${ }^{1}$ PLHIV, including those receiving antiretroviral treatment (ART), have a 30-35 higher risk of developing ${ }^{3}$ and dying of $\mathrm{TB}^{4}$ than HIV-negative individuals. It is therefore paramount that TB patients starting ART are routinely tested for HIV. Unfortunately, despite increasing yearly, the proportion of notified TB cases with a documented HIV result in 2017 was only of $60 \%{ }^{1}$

In this article we review the advances on pathogenesis, diagnosis, treatment, and current challenges for the global control of TB-HIV co-infection.

\section{Pathogenesis of tuberculosis}

Mycobacterium Tuberculosis (MTB) is transmitted by droplet nuclei expelled from the respiratory tract of infected individuals through coughing and, less frequently, through sneezing, laughing and singing. ${ }^{5-7}$ Inhalation and deposition of infected droplet nuclei in the host lung triggers infection, 5,8 where it is recognized and phagocytosed by alveolar macrophages. , $^{6,9}$ Subsequent course of infection, determined by MTB virulence and the host immune response, is mediated by recruitment and activation of alveolar macrophages. Inability of alveolar macrophages to destroy or inhibit MTB results in intracellular proliferation of the pathogen, macrophage cell death and pathogen release, which induces a repeat cycle aimed at limiting further bacterial growth., ${ }^{9,10}$ MTB infected alveolar macrophages secrete cytokines and chemokines that initiate an inflammatory cascade, attracting other phagocytic cells to form a granuloma, the hallmark of TB disease, $, 8,10$ intended to wall-off the pathogen and limit its spread to other organs. Inability of the host immune response to adequately control bacterial replication following first infection with MTB results in primary TB disease. This either heals with persistence of viable organisms or progresses to active TB disease. Erosion of caseous necrotic lesions into airways causing mechanical spread of bacilli results in infectiousness, ${ }^{5}$ whereas systemic infection results from migration of TB-infected cells into the lymphatic and circulatory systems. 5,6,10 While focal lesions are typical of TB, lung biopsy studies demonstrate parenchymal pathology ranging from pulmonary infiltration with an exudative reaction, granulomatous inflammation, fibro-caseous disease, ${ }^{5,8}$ to cavities resulting from necrosis of tuberculous pneumonia.
Post-primary TB disease occurs by reactivation of dormant organisms from previous primary TB infection, or from exogenous re-infection. While a granulomatous process is seen in primary tuberculosis, pathology in post-primary TB follows a pneumonic process characterized by accumulation of foamy macrophages in alveoli of lung apices with acid fast bacilli organisms seen almost exclusively in alveolar macrophages. In high bacillary burden disease, caseous necrosis may evolve into cavities, which may progress slowly for up to a year producing little or no clinical illness.

Active TB disease develops in approximately $5 \%$ of MTB-infected individuals within two years. In 90-95\%, dormant viable bacteria survive for years, progressing to active disease at a rate of $10 \%$ per lifetime and $10 \%$ per annum in HIV-uninfected and PLHIV respectively. ${ }^{11,12}$ The innate immune response through $B$ cells and antibodies mediate MTB killing directly through stimulation of antigen presentation, and cytokine production aimed at enhanced killing of MTB infected macrophages. Quantitative and qualitative depletion of CD4 T-cells during HIV infection increases the risk of MTB disease. Characteristically, this immunologic impairment is associated with impaired granuloma formation, compromised MTB containment and increasing bacillary burden. ${ }^{11,13,14}$ Indeed, the HIV epidemic has played an important role in increasing the prevalence of miliary and extrapulmonary TB globally. In turn, TB enhances HIV viral replication by increasing expression of viral growth receptors such as CXCR4. ${ }^{15}$ Reactivation of latent TB infection is likely precipitated by disruption of the stable host-microbe interaction. ${ }^{15}$ In PLHIV, multiple factors including diversity in lung microenvironments, levels of immune activation and cytokine secretion, and variation in granuloma genesis, cumulatively expose MTB to varying levels of nutrients and oxygen that promote or prohibit replication, influence TB pathogenesis and disease severity. ${ }^{16}$

\section{Diagnosis of tuberculosis among people living with HIV}

\section{Diagnosis of latent tuberculosis}

Two major tests exist for the diagnosis of latent tuberculosis infection: the tuberculin skin test (TST) and the interferon-gamma release assays (IGRA). ${ }^{17}$ A thorough review of these two types of tests is outside the scope of this article. All newly diagnosed PLHIV should be screened for latent tuberculosis with TST or IGRA. ${ }^{18,19}$ Also, those patients tested negative while having low CD4 counts $(<200$ cells $/ \mu \mathrm{L})$, should be retested after immune reconstitution above this threshold. ${ }^{18,20}$ IGRA is generally preferable, if available, particularly for patients with prior vaccination with Bacille Calmette-Guérin (BCG) and for patients who are unlikely to return to have the TST read. It is reasonable to confirm a positive TST result with an IGRA in low TB incidence settings, to rule out nontuberculous mycobacterial infection. ${ }^{21}$ For those who test negative with ongoing risk factors for active TB, annual screening is warranted. Testing should not be repeated among those with a previously positive test. Treatment should be administered to those with a positive TST or IGRA results after having excluded active TB. In high prevalence settings where TST or IGRA are often not available, treatment of latent tuberculosis infection is recommended to all PLHIV regardless of testing results, after having excluded active TB. ${ }^{22}$ 


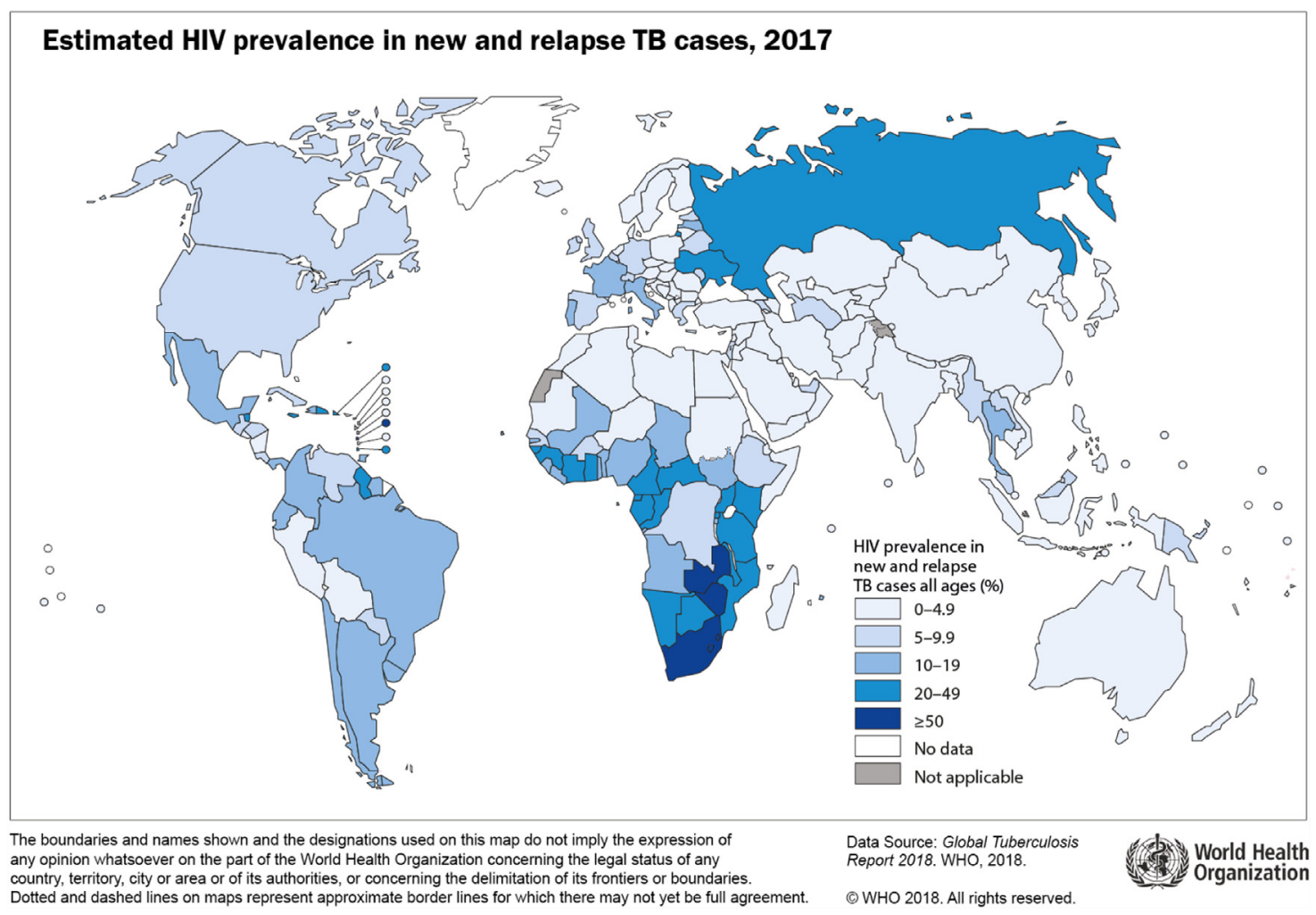

Fig. 1. Estimated HIV prevalence in new and relapse TB cases, 2017. Source: Global tuberculosis report 2018, WHO (1).

Diagnosis of active tuberculosis disease

Diagnosis of active TB disease in PLHIV is challenging due to the differing and non-specific clinical symptoms, and often healthcare workers rely on suggestive radiological changes or clinical suspicion. ${ }^{23,24}$ The level of HIV-associated immunosuppression and the resulting TB burden influences the yield of the different available diagnostic methods, including smear microscopy, culture, PCR, urine lipoarabinomannan, and whole-genome sequencing (Fig. 2).

\section{Smear microscopy}

Historically, diagnosis of TB disease has relied on microscopy (Ziehl-Neelsen staining of Acid-Fast Bacilli) of fluid or tissue from TB-affected organs. Although widely available in laboratories globally, the limited sensitivity of traditional microscopy: $\sim 50 \%$ sensitive for high bacterial burden TB disease (such as cavitary PTB in adults) and $10-20 \%$ sensitive in paucibacillary disease (such as TB-meningitis), has limited its clinical utility. ${ }^{25}$

\section{Culture}

Culture of clinical specimens for MTB has a $50-100 \%$ sensitivity depending on bacillary load and the clinical specimen tested. MTB culture techniques however: are expensive (\$13-\$50/unit); are not universally available; require a biosafety level-3 laboratory; and results takes at least 10 days in liquid media (Mycobacteria Growth Inhibitor Tube culture) and up to 8 weeks on solid media (Löwenstein-Jensen), too slow to aid clinical decision making.

\section{Commercially available PCR platforms}

The introduction of the GeneXpert ${ }^{\circledR}$ MTB/Rif (Xpert) assay (Cepheid, Sunnyvale, CA, USA) a cartridge-based, real-time PCR molecular assay in 2010 marked a new era in TB diagnostics. Xpert

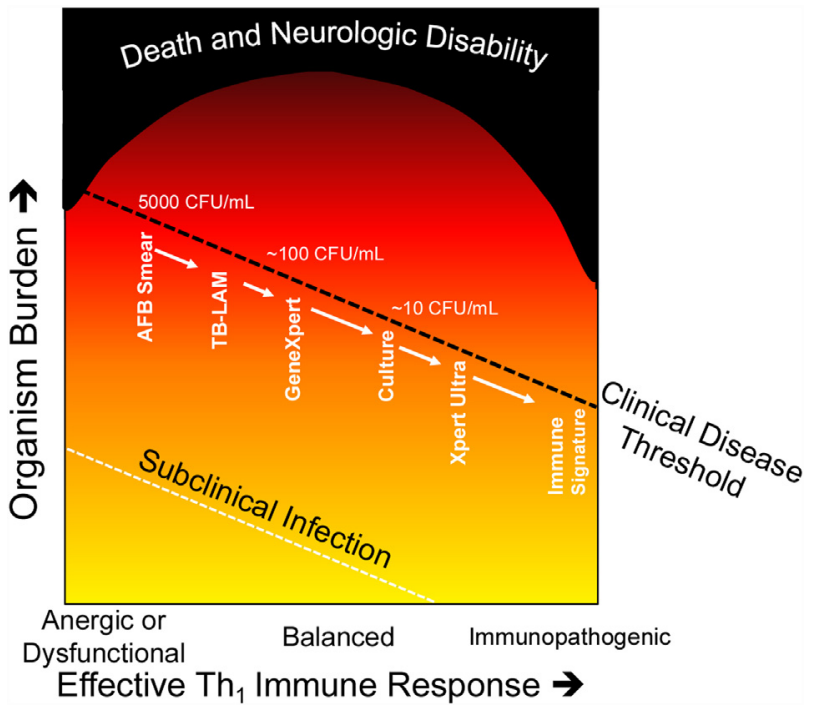

Fig. 2. Damage response framework in relation to Tuberculosis.

Modified from the damage-response framework of microbial pathogenesis. (24). As the immune response is less effective due to HIV-infection, energy or dysfunctional responses (e.g. Th2 or neutrophil response) immune control of the pathogen is less effective, and TB bacilli are more easily detected by microbiologic diagnostics. As a more effective Th1immune response occurs, less viable TB bacilli exist and diagnosis by traditional techniques becomes more challenging. In the extreme, such as in paradoxical immune reconstitution inflammatory syndrome, immunopathology can occur in the absence of viable or detectable organisms. Mortality is highest in those with the most attenuated or exuberant inflammatory responses.

MTB/RIF has notable benefits over traditional microbiology techniques: Xpert MTB/RIF is fully automated and requires minimal operator training; a biosafety level-3 laboratory is not required; and the run-time of $\sim 2 \mathrm{~h}$ enables rapid results turnaround of $\sim 48 \mathrm{~h}$. In addition, Xpert MTB/RIF provides preliminary drug sensitivity 
testing (DST) through detection of rpoB gene mutations conferring rifampicin resistance. In a 2014 Cochrane review evaluating the role of Xpert MTB/RIF in diagnosing PTB, pooled sensitivity and specificity was $89 \%$ (95\% CI 85-92\%) and 99\% (95\% CI 98-99\%), respectively. ${ }^{26}$ In 2011, the WHO issued a strong recommendation for Xpert MTB/RIF to be used as the preferred initial diagnostic test for sputum samples in diagnosing $\mathrm{PTB}^{27}$; followed in 2013, by a recommendation for use with CSF specimens, lymph nodes and other tissues in diagnosing EPTB. ${ }^{26}$ However, the suboptimal sensitivity of Xpert MTB/RIF in paucibacillary disease and among PLHIV is a significant limitation. Pooled sensitivity from seven studies in PLHIV was 79\% (95\% CI 70-86\%). ${ }^{26}$ In 2017, Cepheid therefore introduced GeneXpert ${ }^{\circledR}$ MTB/Rif Ultra (Ultra) a re-engineered version of the Xpert cartridge MTB/RIF platform with technical enhancements, including larger specimen volume, additional probes for two other DNA targets in the mycobacterial genome, optimized fluidics and PCR cycling and addition of a'trace' category for the lowest bacillary load. The improved sensitivity of Ultra is purported to have greatest clinical utility in cohorts of PLHIV. In a multi-center, diagnostic accuracy study, comparing Xpert Ultra and Xpert MTB/RIF in PTB diagnosis, Ultra sensitivity demonstrated a greater additional diagnostic benefit in PLHIV: 13\% difference (95\% CI 6.4-21\%) compared to $1.3 \%$ (95\% CI 1.8-4.9\%) improvement in HIV-uninfected patients. ${ }^{28} \mathrm{~A}$ recent study conducted in Uganda showed a sensitivity of Xpert Ultra of 95\% for diagnosing tuberculous meningitis (TBM), which was higher than Xpert MTB/RIF (45\%) and culture (45\%). ${ }^{29}$ Based on this highly improved sensitivity, the WHO has endorsed Ultra, ${ }^{30}$ including for TBM, and it has been made available to eligible countries at the same concessional pricing as the standard Xpert MTB/RIF cartridge.

\section{Urine lipoarabinomannan (LAM) antigen detection}

The increasing recognition and availability of urine lipoarabinomannan (LAM) antigen detection lateral flow assays marked a significant step forward in the diagnosis of disseminated HIVassociated TB. Urine is easily obtained without risk of aerosolization of MTB and results are available in $20 \mathrm{~min}$, facilitating timely clinical decision making. The sensitivity of LAM is only moderate (pooled sensitivity and specificity across six studies was 44\% (95\% $31-60 \%$ ) and $92 \%$ (95\% 83-96\%), respectively ${ }^{31}$ but its sensitivity is greatest in those with a CD4 count $<100$ cells/ $\mu l$. Moreover, TB-LAM has recently been shown to have demonstrable clinical benefit including increased overall TB diagnoses and significant reduction in mortality in high risk subgroups: CD4 $<100$ cells $/ \mu \mathrm{L}$; and hemoglobin $<8 \mathrm{~g} / \mathrm{dl}$ when hospitalized PLHIV underwent systematic screening. ${ }^{32}$ TB-LAM LFAs are complementary to other diagnostics and at $\sim \$ 4$ per test are potentially a cost-effective intervention when used in the appropriate population.

\section{Whole-genome sequencing}

Whole genome sequencing of MTB for detection of drug resistance and typing is increasingly being used in a range of clinical and research settings. The recently demonstrated capacity to sequence MTB directly from clinical specimens ${ }^{33}$ has the potential to revolutionize the TB diagnosis and DST in both high- and low-income countries. $^{34}$

\section{Treatment of tuberculosis-HIV co-infection}

\section{Treatment of latent tuberculosis}

Isoniazid preventive therapy (IPT) has the potential to deliver greater health benefits to PLHIV in high-incidence countries. ${ }^{35}$ In the TEMPRANO study, a trial designed to assess the benefits of early antiretroviral therapy (ART), 6-month IPT, or both among adult PLHIV with high CD4 + cell counts, immediate ART and 6-month IPT independently decreased the risk of death or HIV-related severe illness compared to deferred ART and no IPT. ${ }^{36}$ Despite its efficacy, several challenges exist hampering the wide roll-out of IPT. Costs, length of treatment and pill burden difficult its implementation and hamper adherence. Moreover, the incidence of TB in sub-Saharan Africa may increase soon after IPT discontinuation. ${ }^{37}$ As a result of these challenges, treatment of latent TB is seldomly available in resource-limited settings (RLS), with only one third of countries currently implementing it among PLHIV. ${ }^{1}$

Shorter treatments, such as the newly recommended weekly high dose isoniazid and rifapentine regimen for12 weeks (3HP), ${ }^{38}$ which have shown to increase adherence to TB preventive treatment ${ }^{39}$ may contribute to a higher implementation in RLS. However, the duration of protection of 3HP is still being evaluated in the WHIP3TB trial (https://clinicaltrials.gov/ct2/show/NCT02980016). Also, availability and authorization of rifapentine is not equally distributed throughout the world. Recently, a combination of daily rifapentine and isoniazid (1HP) for only one month, has been evaluated in the BRIEF trial, showing fewer adverse events and higher adherence compared to 9-months of isoniazid. ${ }^{40}$ The implementation of these regimens in low endemic areas is hampered by the low availability of rifapentine. However, there is already some evidence of a better completion rates and fewer adverse events when using $3 \mathrm{HP} .{ }^{41}$

\section{Treatment of active TB-HIV co-infection}

Early initiation of anti-TB therapy and ART for patients with HIV-associated TB is critical in reducing morbidity and mortality as well as reducing onwards transmission of both infections; several important management challenges however exist: (i) when to start ART; (ii) significant PK drug-drug interactions (DDI); (iii) additive toxicities of concomitant ART and anti-TB drugs; and (iv) TB-associated immune reconstitution inflammatory syndrome (TB-IRIS). The global HIV response serves as one of the most inspiring undertakings in the history of global health. ART rollout has been impressive, with around 24 million people now on ART globally. Several countries worldwide, including Botswana, have met or are on track to meet the UNAIDS 90:90:90 targets (90\% of people living with HIV knowing their status; $90 \%$ of those on ART; and $90 \%$ of people receiving ART virologically suppressed by 2020). ${ }^{42}$ Conversely, TB drug development and roll out has moved more slowly, with no new first-line agents since the 1970s and pill burden and side-effects remaining a huge challenge. It is therefore perhaps not surprising that TB mortality, particularly in HIV co-infection, has failed to decline in line with End-TB targets. In addition, multi-drug resistant TB (MDRTB) poses a growing challenge in many regions. ${ }^{1,43}$ Bedaquiline has been WHO-approved for the treatment of drug-resistant TB for 5 years and will hopefully replace injectable agents (which can cause deafness and kidney injury) but uptake has been slower than anticipated. ${ }^{44}$ Clinical trials are currently underway investigating an all oral short course (6-9-month) regimen for multi-drug (MDR) and extensively-drug resistant (XDR) TB, a welcome alternative to the existing protracted regimen including injectable agents. The nitroimidazoles, delamanid and pretomanid, are less toxic and a useful addition to the armamentarium for the treatment of drugresistant TB. Linezolid, combined with bedaquiline and pretomanid during six months have demonstrated a high success rate, it is safe and can change the paradigm of the therapy of XDR TB. ${ }^{45}$ A number of other novel agents are in the development pipeline (https://www.newtbdrugs.org) and higher dose of rifampicin and 
isoniazid are also being explored as a way of shortening the treatment duration (https://clinicaltrials.gov/ct2/show/NCT02581527).

\section{TB-HIV drug-drug interactions}

Rifamycins, the cornerstone of treatment for drug sensitive TB, are associated with a considerable potential for PK DDI. Rifampicin is a potent inducer of the hepatic CYP450 enzymes (including CYP2A6, CYP2B6, CYP2C, and CYP3A isoenzymes), P-glycoprotein (P-gp), and uridine diphosphate glucuronosyltransferase (UGT) $1 \mathrm{~A} 1$ enzymes. ${ }^{46}$ The magnitude of rifapentine-mediated CYP3A4 induction is predicted to be lower than rifampicin but higher than rifabutin. This induction alters pharmacokinetics of drugs metabolized by these pathways, reducing plasma concentrations of several antiretroviral drugs, which risks loss of efficacy and sequential development of resistance mutations. As a potent enzyme inducer, rifampicin is not recommended for use in patients receiving protease inhibitors $(\mathrm{PI})$, certain non-nucleoside reverse transcriptase inhibitors (NNRTI) such as rilpivirine, nevirapine, and etravirine; some NRTI such as tenofovir-alafenamide; and some integrase strand transfer inhibitors (INSTI), such as elvitegravir and bictegravir. Rifabutin, a weaker CYP3A4 enzyme inducer is recommended as an alternative to rifampicin in patients receiving PI-based ART regimens. Because rifabutin is a substrate of the CYP450 enzyme system however, its metabolism may be affected by NNRTIs or PIs and rifabutin dosage adjustment is generally recommended (Fig. 3). Efavirenz-based ART regimen is recommended as the preferred first-line regimen globally. Recent evidence has shown that dolutegravir, an INSTI which is currently the recommended ART regimens for initial therapy by the WHO guidelines, can be safely co-administered with rifampicin provided they are dose-adjusted to twice daily. ${ }^{22,47,48}$ The recent Reflate TB2 trial, an open-label, phase 3 , randomized clinical trial conducted in Brazil, Côte d'Ivoire, France, Mozambique, and Vietnam comparing another INSTI, raltegravir $400 \mathrm{mg}$ BID vs. efavirenz $600 \mathrm{mg}$ QD with TDF/3TC in PLHIV on standard TB treatment, failed to demonstrate non-inferiority of raltegravir at week $48 .{ }^{49}$

The variety and complexity of DDI are summarized in Fig. 3. Such challenges are particularly stark in lower income settings where the range of available ART is limited, rifabutin is frequently not available, HIV viral load monitoring is not universal, and routine genotyping for HIV resistance profiles is generally not available.

\section{When to start TB treatment and ART}

In patients diagnosed with active TB prior to the initiation of ART, the decision of when to start ART is informed by the risk of further immune decline, additive opportunistic infections and death with delaying ART initiation vs. the risk of TB-IRIS, which is greater with earlier ART initiation. ${ }^{50}$ Several randomized controlled trials have attempted to address the optimal timing of ART initiation. Three large randomized controlled trials, demonstrated that early ART in those with CD 4 counts $<50$ cell $/ \mu$ L significantly reduced AIDS events or deaths. ${ }^{50}$ In patients with CD4 cell counts $<50$ cells $/ \mu \mathrm{L}$ therefore, ART initiation is recommended within the first 2 weeks of TB treatment. For patients with CD4 $>50 \mathrm{cell} / \mu \mathrm{L}$, ART initiation should be within eight weeks of starting anti-TB therapy. ${ }^{46}$ These recommendations also apply to patients with suspected or confirmed MDR-TB. ${ }^{46}$ A randomized placebo-controlled trial conducted in South Africa, Tanzania, Uganda and Zambia in 2014, and randomizing 1675 patients with CD4 counts of 220 cells/ $\mu$ l or more to early ART vs ART delayed at the end of six months of TB treatment, did not find differences in TB treatment failure, TB recurrence or death. These results suggest that ART can be delayed until the completion of TB treatment among this subgroup of patients and challenge the current WHO recommendations. ${ }^{51}$

\section{TB immune reconstitution inflammatory syndrome}

TB-IRIS is caused by ART-induced restoration of TB-specific immune responses, resulting in either the deterioration of a treated infection (paradoxical IRIS) or a new presentation of a previously subclinical infection (unmasking IRIS). IRIS has been reported in $8-40 \%$ following ART initiation. ${ }^{52}$ Predictors of IRIS include a baseline CD4 count $<50$ cells/ $\mu \mathrm{L}$; rapid on-ART restoration of CD4 counts; high pre-ART and lower on-ART HIV viral loads; and severity of TB disease. Most TB-IRIS occurs within 3 months of the start of ART, usually within the first month. Incidence of unmasking TB-IRIS is harder to quantify but there is concern that the recent rapid upscaling of 'HIV test and start,' could result in an increased incidence of unmasking IRIS events to opportunistic infections. ${ }^{53}$

TB-IRIS ranges from mild to severe to life-threatening. Patients with mild or moderately severe IRIS can be managed symptomatically. For management of severe TB-IRIS, corticosteroids are recommended as demonstrated in a recent RCT, although data on the optimal dose, duration, and overall safety and efficacy are limited. ${ }^{54}$ In the presence of IRIS, ideally neither TB therapy nor ART should be stopped, as immune restoration and effective control of the bacillary burden are both essential to long term survival.

TB-IRIS prevention with prednisolone prophylaxis $(40 \mathrm{mg} /$ day for 2 weeks then $20 \mathrm{mg} /$ day for 2 weeks started with ART) was investigated in a recent clinical trial among ART-naïve adults at high risk of TB-IRIS (within 30 days of TB treatment initiation and CD4 count $\leq 100$ cells $/ \mu \mathrm{L}$ ). Grade 3 adverse events occurred more frequently in the placebo arm ( $45.4 \%$ vs. $29.4 \%, p=0.01)$, but grade 4 adverse events were similar by $\operatorname{arm}(8.4 \%$ vs. $7.6 \%, p=0.81)$. The intervention reduced the risk of TB-IRIS by $30 \%$ and further reduced the requirement for corticosteroids to treat TB-IRIS by $53 \% .{ }^{55}$

\section{Present areas of uncertainty}

Tuberculous meningitis is the most severe form of HIVassociated TB. TBM-associated mortality is $40-58 \%$ in PLHIV. Given that the risks of TB-IRIS is significantly greater in CNS disease, caution with ART initiation is required. In a study conducted in Vietnam, TBM patients were randomized to immediate ART or to ART deferred 2 months after initiation of TB treatment. A significantly higher rate of severe adverse events was seen in patients who received immediate ART than in those with deferred therapy $(80.3 \%$ vs. $69.1 \%$ for early and deferred ART, respectively; $p=0.04) .{ }^{56}$ There have been no subsequent studies to further delineate the optimum timing of ART in TBM and current expert opinion is to start at 8 weeks. The use of adjuvant steroids in the treatment of extrapulmonary TB disease, namely TBM and pericardial TB, also requires further study in PLHIV. In TBM, the WHO currently recommends initial adjuvant dexamethasone or prednisolone tapered over 6-8 weeks. However, of the nine trials which demonstrated a mortality benefit of adjunctive steroids in the treatment of TBM, ${ }^{57}$ only one trial from Asia included PLHIV. In the sub-group analysis of PLHIV, there was a non-significant reduction in mortality and no reduction in long term neurological disability. ${ }^{58}$ Although adjunct steroids remain standard of care for patients with HIV-associated TBM, a currently recruiting study in PLHIV will provide important trial data to further inform clinical practice. ${ }^{59}$ Finally, an Indian trial randomizing patients with TBM to receive aspirin or placebo as adjuvant to antitubercular treatment showed an absolute risk reduction of stroke in $19 \%$ and a $21.7 \%$ reduction in three-month mortality. ${ }^{60}$

There is considerable hope that scale up of HIV "test and start" and IPT uptake will reduce TB/HIV incidence and mortality. 
However, ongoing evolution of MTB and HIV drug resistance is a competing challenge for which potent, tolerable, affordable and available drugs are the only answer. Moreover, IRIS is likely to pose an ongoing clinical challenge for which other safe host-directed therapies are required.

\section{Challenges of TB/HIV co-infection in resource-limited settings}

The deadly TB/HIV association remains a major public health concern in RLS. Still today, TB is the main cause of morbidity and mortality amongst PLHIV. In turn, HIV represents the main TB epidemic driver in certain regions. TB develops more frequently, recurs more likely and often remains undiagnosed and untreated in PLHIV. ${ }^{1,61}$ This threat is exacerbated by the growing prevalence of DR-TB. Since 2004, the WHO recommends a'collaborative HIV/TB activities' package consisting in integrating service delivery, reducing TB burden through early ART initiation and reducing HIV burden in patients with presumptive and diagnosed $\mathrm{TB}^{62}$ (Table 1). In RLS, the clinical challenges managing HIV/TB co-infection are aggravated by programmatic issues related to outdated policies and practices. Improved diagnostics, cheaper, more effective anti-TB regimens and improved ART coverage are some of the main challenges ahead alongside limitations in human, financial resources and health infrastructure. ${ }^{63}$

In 2017 in the highest TB/HIV burden countries, 66\% of patients with TB were aware of their HIV status. ${ }^{1}$ However, merely $46 \%$ of estimated incident TB cases amongst PLHIV were reported, leaving an enormous gap of PLHIV with non-identified TB, despite systematic TB screening for PLHIV is broadly recommended. Diagnostic gaps remain a big challenge, the cost-effectiveness of Xpert MTB/RIF is controversial, and only half of the countries recommending initial Xpert MTB/RIF testing in PLHIV are implementing

\begin{tabular}{|c|c|c|c|c|c|c|c|c|c|c|c|c|c|c|c|c|c|c|c|c|}
\hline & Class & \multicolumn{6}{|c|}{ NRTIs } & \multicolumn{4}{|c|}{ NNRTIs } & \multicolumn{3}{|c|}{ INSTIs } & \multicolumn{5}{|c|}{ Pls } & \multirow[b]{2}{*}{ 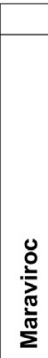 } \\
\hline & & 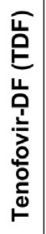 & 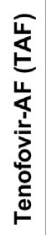 & 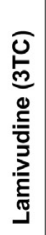 & 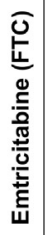 & 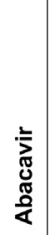 & 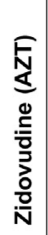 & 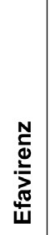 & 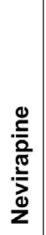 & 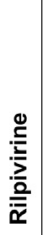 & 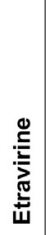 & 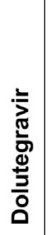 & 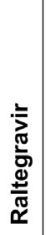 & 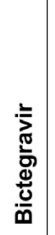 & 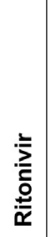 & 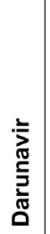 & 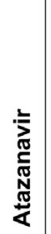 & 产 & $\begin{array}{l}\frac{\pi}{\pi} \\
\frac{00}{0} \\
\frac{0}{0} \\
0 \\
0\end{array}$ & \\
\hline \multirow{6}{*}{ 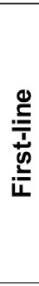 } & Rifampicin & 4 & $\mathrm{~b}$ & 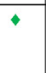 & $\rightarrow$ & $\mathrm{u}^{*}$ & $\mathrm{c}$ & $\mathrm{d}$ & 1 & 1 & 1 & $\mathrm{~m}$ & $\mathrm{~m}$ & 3 & 4 & ${ }_{4}$ & & & & $\mathrm{~s}$ \\
\hline & Rifabutin & - & $\mathrm{b}$ & 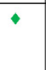 & 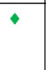 & • & $\bullet$ & e & $x$ & 2 & k & - & • & 3 & o & & o & & 0 & $t$ \\
\hline & Rifapentine & + & $\mathrm{b}$ & 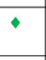 & 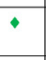 & $\rightarrow$ & $\bullet$ & & i. & & $1^{*}$ & & $\mathrm{n}$ & $3^{*}$ & $\mathrm{p}^{*}$ & $\mathrm{p}^{*}$ & $\mathrm{p}^{*}$ & $\mathrm{p}^{*}$ & & $p^{*}$ \\
\hline & Isoniazid & 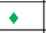 & 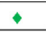 & 4 & $\bullet$ & + & $\bullet$ & + & 4 & 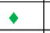 & + & + & + & 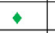 & + & 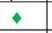 & 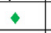 & 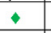 & + & + \\
\hline & Pyrazinamide & 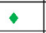 & + & + & 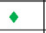 & + & - & + & + & 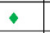 & + & + & + & + & + & + & 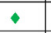 & + & 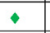 & 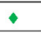 \\
\hline & Ethambutol & + & + & + & + & + & 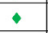 & + & + & 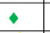 & + & 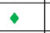 & + & + & 4 & 4 & + & + & + & + \\
\hline \multirow{5}{*}{ 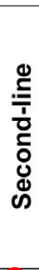 } & Moxifloxacin & 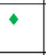 & $\bullet$ & $\bullet$ & $\bullet$ & + & $\bullet$ & $\mathrm{g}^{*}$ & $\bullet$ & j & $\mathrm{g}$ & $\bullet$ & $\bullet$ & $\bullet$ & 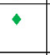 & - & $\square$ & & - & $\bullet$ \\
\hline & $\begin{array}{l}\text { Ofloxacin I } \\
\text { Levofloxacin }\end{array}$ & $\bullet$ & $\bullet$ & $v^{*}$ & $\bullet$ & $\bullet$ & $\bullet$ & & & j & 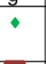 & $\bullet$ & $\bullet$ & - & - & 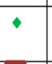 & $q$ & $q$ & - & - \\
\hline & Bedaquiline & $\bullet$ & $\bullet$ & + & $\bullet$ & 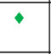 & $\bullet$ & h & $\bullet$ & $j^{*}$ & L & 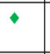 & 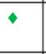 & 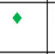 & $r$ & $r$ & $r$ & $r$ & & $\bullet$ \\
\hline & $\begin{array}{l}\text { Pretomanid / } \\
\text { Delamanid }\end{array}$ & + & * & $4^{*}$ & + & $4^{*}$ & $4^{*}$ & 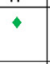 & * & * & * & & & & y & $y^{*}$ & $y^{*}$ & $y$ & & * \\
\hline & $\begin{array}{l}\text { Aminoglycosi } \\
\text { des }\end{array}$ & $a^{*}$ & 4 & $a^{*}$ & 4 & 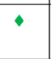 & $\bullet$ & 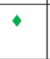 & $\bullet$ & $\bullet$ & • & $\bullet$ & • & 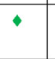 & 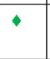 & 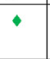 & 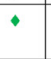 & 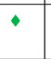 & 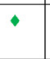 & 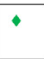 \\
\hline \multicolumn{21}{|c|}{$\begin{array}{l}\text { Strong interactions } \\
\text { 1. Rifamycins are a potent inducer of CYP450 enzymes. The magnitude of rifapentine-mediated CYP3A4 induction is predicted to be } \\
\text { lower than rifampicin but higher than rifabutin. Nevirapine, rilpivirine and etravirine should not be used with rifampicin as co- } \\
\text { administration may cause significant decreases in NNRTI concentrations and loss of therapeutic effect. No formal interaction studies } \\
\text { with rifapentine yet. } \\
\text { 2. Co-administration is contraindicated in the US Prescribing Information, but the European SPC recommends the do se of rilpivirine } \\
\text { should be increased to } 50 \mathrm{mg} \text { o.d. during co-administration (and decreased to } 25 \mathrm{mg} \text { o.d. when rifabutin is stopped). } \\
\text { 3. Co-administration of rifampicin and rifabutin with a single dose of bictegravir ( } 75 \mathrm{mg} \text { stat) decreased bictegravir C } \text { max }^{\text {and }} \text { AUC. Co- } \\
\text { administration not recommended. } \\
\text { 4. Co-administration contraindicated as it may significantly decrease concentrations of the PI, leading to loss of therapeutic effect } \\
\text { and possible development of resistance. } \\
\text { 5. Co-administration of twice daily atazanavir alone with rifampicin failed to provide adequate atazanavir exposure and a high } \\
\text { frequency of liver reactions was seen. } \\
\text { 6. Adequate exposure to lopinavir/ritonavir may be achieved when } 400 / 400 \mathrm{mg} \text { twice daily is used but this is associated with a higher } \\
\text { risk of liver and gastrointestinal toxicity. Therefore, this co-administration should be avoided unless judged strictly necessary. }\end{array}$} \\
\hline \multicolumn{21}{|c|}{$\begin{array}{l}\text { Potential interactions } \\
\text { a. Co-administration with drugs that reduce renal function or compete for active tubular secretion may increase concentrations of } \\
\text { either drug. Avoid with concurrent or recent use of a nephrotoxic agent. If unavoidable, renal function should be monitored weekly. } \\
\text { b. Rifamycins are inducers which may results in lower exposure of TAF. Co-administration is not recommended, but if unavoidable, } \\
\text { TAF } 25 \mathrm{mg} \text { b.d. may provide comparable exposures to those observed with TAF } 25 \mathrm{mg} \text { o.d. in the absence of rifampicin. } \\
\text { c. Rifampicin significantly decreased AZT AUC }(47 \%) \text { and } \mathrm{C}_{\max }(43 \%) \text {. This may result in a partial loss or total loss of efficacy of } \\
\text { AZT. } \\
\text { d. Studies (in African \& Asian populations) indicate either that there is no clinically significant effect of rifampicin on efavirenz } \\
\text { exposure so most guidelines recommend that efavirenz is used at } 600 \mathrm{mg} \text { o.d. In the absence of efficacy data, patients maintained } \\
\text { on efavirenz } 400 \mathrm{mg} \text { o.d. should increase to efavirenz } 600 \mathrm{mg} 0 . \mathrm{d} \text {. while treated with rifampicin. } \\
\text { e. Co-administration of rifabutin ( } 300 \mathrm{mg} \text { o.d.) and efavirenz }\left(600 \mathrm{mg} \text { o.d.) decreased rifabutin } \mathrm{C}_{\text {max }}(32 \%) \text {, AUC (38\%) and } \mathrm{C}_{\text {min }}\right. \\
\text { (45\%). Efavirenz } \mathrm{C}_{\text {min }} \text { decreased by } 12 \% \text {, but there was no change in } \mathrm{C}_{\text {max }} \text { or AUC. Increase daily doses of rifabutin by } 50 \% \text {; } \\
\text { consider doubling rifabutin doses in regimens where rifabutin is given } 2-3 \text { times a week. The clinical effect of dose adjustment has } \\
\text { not been adequately evaluated. Individual tolerability and virological response should be considered when making the dose } \\
\text { adjustment. }\end{array}$} \\
\hline
\end{tabular}

Fig. 3. Summary of drug-drug interactions between commonly used antiretroviral and antituberculous agents.

The website www.hiv-druginteractions.org should be used for up-to-date and more detailed interaction details. 


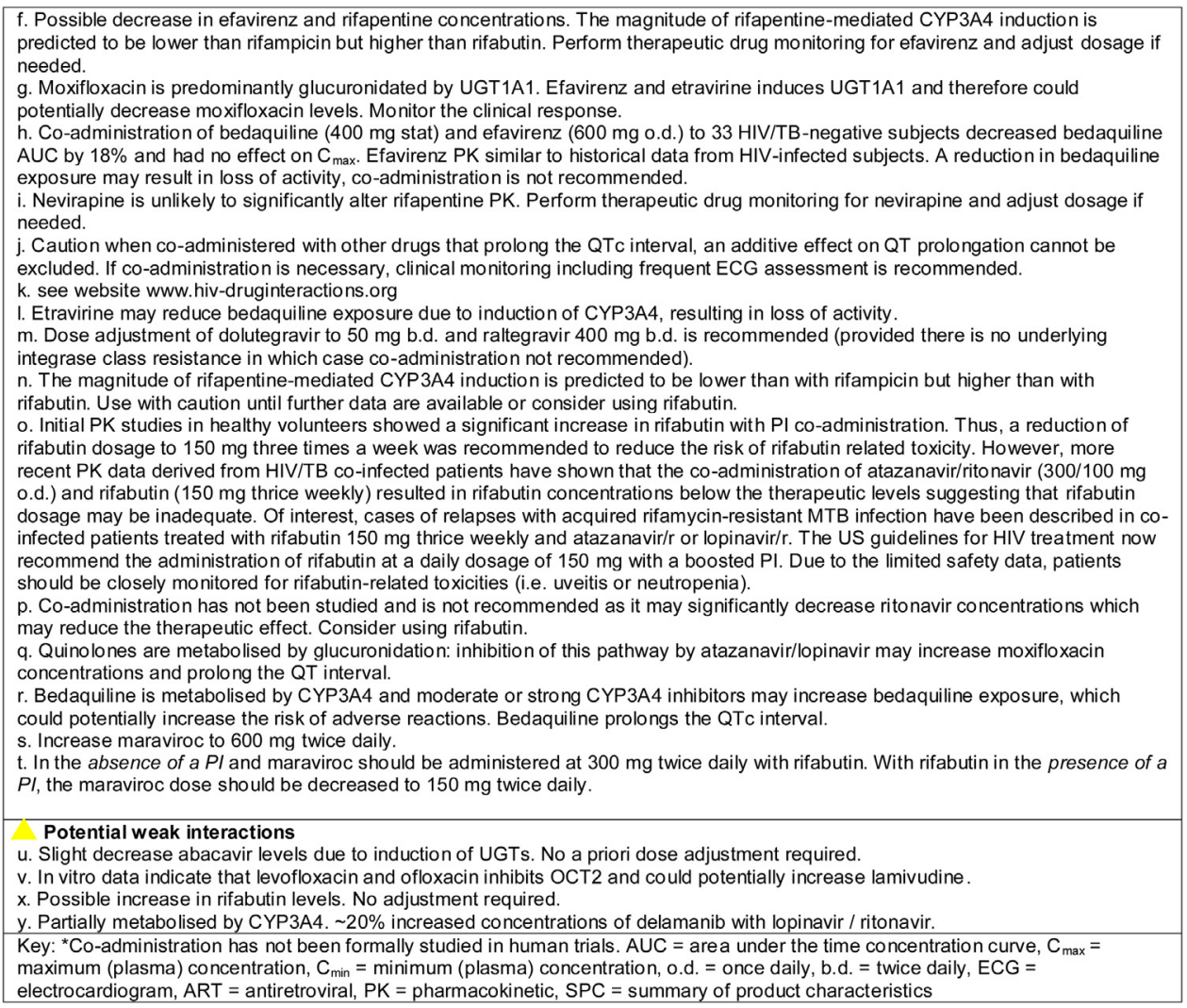

Fig. 3. (Continued)

Table 1

EndTB strategy pillars and components.

Pillars

Integrated, patient-centered care and prevention

Bold policies and supportive systems

Intensified research and innovation

Components

Early diagnosis of tuberculosis including universal drug-susceptibility testing,and systematic screening of contacts and high-risk groups

Treatment of all people with tuberculosis including drug-resistant tuberculosis, and patient support

Collaborative tuberculosis/HIV activities, and management of co-morbidities

Preventive treatment of persons at high risk, and vaccination against tuberculosis

Political commitment with adequate resources for tuberculosis care and prevention Engagement of communities, civil society organizations, and public and private care providers Universal health coverage policy, and regulatory frameworks for case notification, vital registration, quality and rational use of medicines, and infection control

Social protection, poverty alleviation and actions on other determinants of tuberculosis

Discovery, development and rapid uptake of new tools, interventions and strategies Research to optimize implementation and impact, and promote innovations

Adapted from WHO http://www.who.int/tb/post2015_TBstrategy.pdf.

it. ${ }^{64-66}$ With advanced HIV disease rates globally plateauing and being TB a leading cause of death in these patients, the effective implementation of newer tools like TB-LAM, proven to reduce mortality, are essential. ${ }^{64,66}$ However, despite the WHO recommendation, TB-LAM implementation is rare, not included in guidelines and often confined to research use. ${ }^{67}$ Also, TB diagnostics in children, access to child-friendly drug formulations, drug-sensitivity testing and access to second line anti-TB drugs pose additional challenges. ${ }^{39,68,69}$

In addition, despite knowing that ART reduces TB risk, ART coverage among TB-patients remains suboptimal in RLS. The wide and safe implementation of the "Test and Start" strategy together with the roll-out of new ARVs such as Dolutegravir could further impact TB incidence.

Moreover, as mentioned, only a third of countries with TB prevention recommendations are implementing latent $\mathrm{TB}$ treatment among PLHIV. Despite shorter effective strategies are available uptake is still limited. ${ }^{70-73}$

ART and TB service decentralization, task-shifting and onestop integrated services increases uptake, improves outcomes and lowers patient costs. ${ }^{74-80}$ Nevertheless, in many settings and in particular in West and Central Africa, with very low ART coverage and centralized and vertical TB and HIV programs, dedicated efforts to HIV/TB integration should be considered. ${ }^{81}$ Finally, TB screening as part of services like ante-natal care remains challenging. ${ }^{82}$ Additional barriers relate to funding, being HIV/TB integration the TB programmatic component with lower funding allocation. This leaves countries relying on partnerships with other departments or organizations. ${ }^{1}$ Furthermore, monitoring and evaluation systems are often not in place; improvements on indicators measuring ART impact and TB prevention are required. Collaborative TB/HIV activities are a pillar of the EndTB strategy yet, outcome data in RLS is 
lacking ${ }^{83}$ (Table 1). Finally, social barriers related to health seeking behavior, stigma or lack of community mobilization are not always addressed. Research agendas in RLS should aim to urgently answer these remaining gaps.

\section{Conclusions}

More than twenty years after the advent of ART, and despite wide effective roll-out in resource-limited settings during the past two decades, TB-HIV co-infection remains as a significant global health challenge. TB-HIV co-infection affects millions of people worldwide and threatens global public health. Several barriers exist for the delivery of optimal patient centered TB and HIV prevention and care. Joint action between TB and HIV programs is needed to overcome these barriers and reduce the global burden of this deadly interaction. Fighting TB/HIV co-infection requires strong political commitment to adopt a comprehensive service integration. While countries are making progress, much work remains to be done to ensure policy adoption and implementation across all communities globally.

\section{Funding}

EL is supported by a Beatriu de Pinós Grant from the Agency for Management of University and Research Grants of the Generalitat de Catalunya (AGAUR, 2016 BP 00204). JMM received a personal 80:20 research grant from the Institut d'Investigacions Biomèdiques August Pi i Sunyer (IDIBAPS), Barcelona, Spain, from 2017 to 2019. FVC is supported by a Wellcome Clinical PhD Fellowship.

\section{Conflict of interests}

The authors declare not having conflicts of interest related to this work. EL has received consulting honoraria from ViiV Healthcare. JMM has received consulting honoraria and/or research grants from AbbVie, Angelini, Bristol-Myers Squibb, Contrafect, Janssen, Genentech, Gilead Sciences, Medtronic, Merck, Novartis, Pfizer, and ViiV Healthcare, outside the submitted work.

\section{Acknowledgements}

ISGlobal is a member of the CERCA Programme, Generalitat de Catalunya.

\section{References}

1. WHO | Global tuberculosis report 2018. WHO; 2018. p. 1-277.

2. García-Basteiro AL, Brew J, Williams B, Borgdorff M, Cobelens F. What is the true tuberculosis mortality burden? Differences in estimates by the World Health Organization and the Global Burden of Disease study. Int J Epidemiol. 2018;47:1549-60.

3. Getahun H, Gunneberg C, Granich R, Nunn P. HIV infection-associated tuberculosis: the epidemiology and the response. Clin Infect Dis Off Publ Infect Dis Soc Am. 2010;50 Suppl. 3(s3):S201-7.

4. Harries AD, Lawn SD, Getahun H, Zachariah R, Havlir DV. HIV and tuberculosis-science and implementation to turn the tide and reduce deaths. J Int AIDS Soc. 2012;15:17396.

5. Rich AR. The pathogenesis of tuberculosis; 1954.

6. Muttil P, Wang C, Hickey AJ. Inhaled drug delivery for tuberculosis therapy. Pharm Res. 2009;26:2401-16.

7. Pai M, Behr MA, Dowdy D, Dheda K, Divangahi M. Tuberculosis. Nat Rev Dis Primers. 2016;2:16076.

8. Dannenberg AM. Pathogenesis of pulmonary tuberculosis. Am Rev Respir Dis. 1982;125 Pt 2:25-9.

9. Orme IM, Robinson RT, Cooper AM. The balance between protective and pathogenic immune responses in the TB-infected lung. Nat Immunol. 2015;16:57-63.

10. Dharmadhikari AS, Kabadi M, Gerety B, Hickey AJ, Fourie PB, Nardell E. Phase I, single-dose, dose-escalating study of inhaled dry powder capreomycin: a new approach to therapy of drug-resistant tuberculosis. Antimicrob Agents Chemother. 2013;57:2613-9.

11. Burman WJ, Jones BE. Clinical and radiographic features of HIV-related tuberculosis. Semin Respir Infect. 2003;18:263-71.

12. Shankar EM, Vignesh R, Ellegård R, Barathan M, Chong YK, Bador MK, et al. HIVMycobacterium tuberculosis co-infection: a "danger-couple model" of disease pathogenesis. Pathog Dis. 2014;70:110-8.

13. Jones BE, Young SM, Antoniskis D, Davidson PT, Kramer F, Barnes PF. Relationship of the manifestations of tuberculosis to CD4 cell counts in patients with human immunodeficiency virus infection. Am Rev Respir Dis. 1993;148: $1292-7$.

14. Di Perri G, Cazzadori A, Vento S, Bonora S, Malena M, Bontempini L, et al Comparative histopathological study of pulmonary tuberculosis in human immunodeficiency virus-infected and non-infected patients. Tuber Lung Dis Off J Int Union Tuberc Lung Dis. 1996;77:244-9.

15. Achkar JM, Jenny-Avital ER. Incipient and subclinical tuberculosis: defining early disease states in the context of host immune response. J Infect Dis. 2011;204 Suppl. 4:S1179-86.

16. Drain PK, Bajema KL, Dowdy D, Dheda K, Naidoo K, Schumacher SG, et al. Incipient and subclinical tuberculosis: a clinical review of early stages and progression of infection. Clin Microbiol Rev. 2018;31, e00021-18.

17. Getahun H, Matteelli A, Chaisson RE, Raviglione M. Latent Mycobacterium tuberculosis infection. N Engl J Med. 2015;372:2127-35.

18. Elzi L, Schlegel M, Weber R, Hirschel B, Cavassini M, Schmid P, et al. Reducing tuberculosis incidence by tuberculin skin testing, preventive treatment, and antiretroviral therapy in an area of low tuberculosis transmission. Clin Infect Dis Off Publ Infect Dis Soc Am. 2007;44:94-102.

19. World Health Organization. Latent tuberculosis infection: updated and consolidated guidelines for programmatic management. Geneva: World Health Organization; 2018. p. 1-78.

20. Fisk TL, Hon H-M, Lennox JL, Fordham von Reyn C, Horsburgh CR. Detection of latent tuberculosis among HIV-infected patients after initiation of highly active antiretroviral therapy. AIDS Lond Engl. 2003;17:1102-4.

21. Muñoz L, Santin M, Alcaide F, Ruíz-Serrano MJ, Gijón P, Bermúdez E, et al QuantiFERON-TB gold in-tube as a confirmatory test for tuberculin skin test in tuberculosis contact tracing: a noninferiority clinical trial. Clin Infect Dis Off Publ Infect Dis Soc Am. 2018;66:396-403.

22. World Health Organization. Consolidated guidelines on HIV prevention, diagnosis, treatment and care for key populations-2016 update; 2016.

23. Lienhardt C, Raviglione M, infectious MSJ of, 2012. New drugs for the treatment of tuberculosis: needs, challenges, promise, and prospects for the future. academic.oup.com.

24. Bassett IV, Wang B, Chetty S, Infectious JGC. Intensive tuberculosis screening for HIV-infected patients starting antiretroviral therapy in Durban, South Africa. academic.oup.com; 2010.

25. Keshinro B, Diul MY. HIV-TB: epidemiology, clinical features and diagnosis of smear-negativeTB. Trop Doct. 2016;36:68-71

26. Steingart KR, Schiller I, Horne DJ. Xpert ${ }^{\circledR}$ MTB/RIF assay for pulmonary tuberculosis and rifampicin resistance in adults-The Cochrane Database of Systematic Reviews published by John . . ; 2014.

27. World Health Organization - Policy statement: automated real-time ..., 2011. Policy statement: automated real-time nucleic acid amplification technology for rapid and simultaneous detection of tuberculosis and rifampicin resistance: Xpert MTB .... cabdirect.org.

28. Dorman SE, Schumacher SG, Alland D, Nabeta P, Armstrong DT, King B, et al Xpert MTB/RIF Ultra for detection of Mycobacterium tuberculosis and rifampicin resistance: a prospective multicentre diagnostic accuracy study. Lancet Infect Dis. 2018;18:76-84.

29. Bahr NC, Nuwagira E, Evans EE, Cresswell FV, Bystrom PV, Byamukama A et al. Diagnostic accuracy of Xpert MTB/RIF Ultra for tuberculous meningitis in HIV-infected adults: a prospective cohort study. Lancet Infect Dis. 2018;18: $68-75$.

30. World Health Organization. WHO meeting report of a technical expert consultation: non-inferiority analysis of Xpert M.T; 2017.

31. World Health Organization. The use of lateral flow urine lipoarabinomannan assay (LF-LAM) for the diagnosis and screening of active tuberculosis in people living with HIV: policy ...; 2015.

32. Gupta-Wright A, Corbett EL, van Oosterhout JJ, Wilson D, Grint D, AlufandikaMoyo M, et al. Rapid urine-based screening for tuberculosis in HIV-positive patients admitted to hospital in Africa (STAMP): a pragmatic, multicentre, parallel-group, double-blind, randomised controlled trial. Lancet 2018;392:292-301.

33. Brown AC, Bryant JM, Einer-Jensen K, Holdstock J, Houniet DT, Chan JZM, et al. Rapid whole-genome sequencing of mycobacterium tuberculosis isolates directly from clinical samples. J Clin Microbiol. 2015;53:2230-7.

34. Lee RS, Pai M. Real-time sequencing of mycobacterium tuberculosis: are we there yet? J Clin Microbiol. 2017;55:1249-54.

35. Dye C, Williams BG. Eliminating human tuberculosis in the twenty-first century J R Soc Interface. 2008;5:653-62.

36. Danel C, Moh R, Gabillard D, Badje A, Le Carrou J, et al., TEMPRANO ANRS 12136 Study Group. A trial of early antiretrovirals and isoniazid preventive therapy in Africa. N Engl J Med. 2015;373:808-22.

37. Samandari T, Agizew TB, Nyirenda S, Tedla Z, Sibanda T, Shang N, et al. 6-month versus 36-month isoniazid preventive treatment for tuberculosis in adults with HIV infection in Botswana: a randomised, double-blind, placebo-controlled trial. Lancet Lond Engl. 2011;377:1588-98. 
38. Hamada Y, Ford N, Schenkel K, Getahun H. Three-month weekly rifapentine plus isoniazid for tuberculosis preventive treatment: a systematic review. Int J Tuberc Lung Dis Off J Int Union Tuberc Lung Dis. 2018;22:1422-8.

39. Rabie H, Frigati L, Hesseling AC, Garcia-Prats AJ. Tuberculosis: opportunities and challenges for the 90-90-90 targets in HIV-infected children. J Int AIDS Soc. 2015;18 Suppl. 6:2023-6.

40. Swindells S, Ramchandani R, Gupta A, Benson CA, Leon-Cruz J, Mwelase N, et al. One month of rifapentine plus isoniazid to prevent HIV-related tuberculosis. N Engl J Med. 2019;380:1001-11.

41. Borisov AS, Bamrah Morris S, Njie GJ, Winston CA, Burton D, Goldberg S, et al. Update of recommendations for use of once-weekly isoniazid-rifapentine regimen to treat latent mycobacterium tuberculosis infection. MMWR Morb Mortal Wkly Rep. 2018;67:723-6.

42. UNAIDS. 90-90-90: an ambitious treatment target to help end the AIDS epidemic; 2014. p. 1-40.

43. Millard J, Ugarte-Gil C, Moore DAJ. Multidrug resistant tuberculosis. BMJ 2015;350:h882.

44. World Health Organization. Joint meeting of the global GLC Committee and the MDR-TB Core Group. Geneva: World Health Organization; 2013, 18-19 April 2013, Switzerland: meeting report.

45. Conradie F, Diacon A, Howell P, Everitt D, Crook A, Mendel C, et al. Sustained high rate of successful treatment outcomes: interim results of 75 patients in the Nix-TB clinical study of pretomanid, bedaquiline and linezolid. In: The Hague, Netherlands; 2018

46. World Health Organization. Guidelines for the treatment of drug-susceptible tuberculosis and patient care; 2017.

47. Dooley KE, Kaplan R, Mwelase N, Grinsztejn B, Ticona E, Lacerda M, et al. Dolutegravir-based antiretroviral therapy for patients co-infected with tuberculosis and Hiv: a multicenter, noncomparative, open-label, randomized trial. Clin Infect Dis Off Publ Infect Dis Soc Am. 2019.

48. Pozniak A. BHIVA guidelines for the management of TB in adults living with HIV [Internet]. BHIVA. 2018. Available from: https://www.bhiva.org/file/5c485f3dc7c17/BHIVA-TB-guidelines.pdf

49. De Castro N, Marcy O, Chazallon C, Messou E, Eholié S, Bhatt N, et al., for the ANRS 12300 Reflate TB2 study group. Virologic efficacy of raltegravir vs. efavirenzbased antiretroviral treatment in HIV1-infected adults with tuberculosis: W48 results of the ANRS 12300 Reflate TB2 trial. In: IAS 2019. 2019. Available from: http://programme.ias2019.org/Abstract/Abstract/2977

50. Abdool Karim SS, Naidoo K, Grobler A, Padayatchi N, Baxter C, Gray AL, et al. Integration of antiretroviral therapy with tuberculosis treatment. N Engl J Med. 2011;365:1492-501.

51. Mfinanga SG, Kirenga BJ, Chanda DM, Mutayoba B, Mthiyane T, Yimer G, et al. Early versus delayed initiation of highly active antiretroviral therapy for HIVpositive adults with newly diagnosed pulmonary tuberculosis (TB-HAART): a prospective, international, randomised, placebo-controlled trial. Lancet Infect Dis. 2014:14:563-71.

52. Meintjes G, Lawn SD, Scano F, Maartens G, Elliott JH, et al. Dis MFLI, a. Tuberculosis-associated immune reconstitution inflammatory syndrome: case definitions for use in resource-limited settings; 2010.

53. Abassi M, Rhein J, Meya DB, Boulware DR. Cryptococcal disease in the era of "Test and Treat": is there cause for concern? Open Forum Infect Dis. 2018;5:ofx274.

54. Meintjes G, Wilkinson RJ, Morroni C, Pepper DJ, Rebe K, Rangaka MX, et al. Randomized placebo-controlled trial of prednisone for paradoxical tuberculosis-associated immune reconstitution inflammatory syndrome. AIDS Lond Engl. 2010;24:2381-90.

55. Meintjes G, Steck C, Blumenthal L, Thienemann F, Schutz C, Buyze J, et al. Prednisone for the prevention of paradoxical tuberculosis-associated IRIS. N Engl J Med. 2018;20:1915-25.

56. Török ME, Yen NTB, Chau TTH, Mai NTH, Phu NH, Mai PP, et al. Timing of initiation of antiretroviral therapy in human immunodeficiency virus (HIV)-associated tuberculous meningitis. Clin Infect Dis Off Publ Infect Dis Soc Am. 2011;52:1374-83.

57. Prasad K, Singh MB, Ryan H. Corticosteroids for managing tuberculous meningitis. Cochrane Database Syst Rev. 2016;4:CD002244.

58. Thwaites GE, Nguyen DB, Nguyen HD, Hoang TQ, Do TTO, Nguyen TCT, et al. Dexamethasone for the treatment of tuberculous meningitis in adolescents and adults. N Engl J Med. 2004:351:1741-51.

59. Donovan J, Phu NH, Mai NTH, Dung LT, Imran D, Burhan E, et al. Adjunctive dexamethasone for the treatment of HIV-infected adults with tuberculous meningitis (ACT HIV): study protocol for a randomised controlled trial. Wellcome Open Res. 2018;3:31.

60. Misra UK, Kalita J, Nair PP. Role of aspirin in tuberculous meningitis: a randomized open label placebo controlled trial. J Neurol Sci. 2010;293:12-7.
61. UNAIDS. Miles to go-closing gaps, breaking barriers, righting injustices; 2018. 62. World Health Organization - WHO policy on collaborative TB/HIV activities .... 2012. WHO policy on collaborative TB/HIV activities: guidelines for national programmes and other stakeholders.

63. Tiberi S, Carvalho ACC, Sulis G, Vaghela D, Rendon A, Mello FC, et al. The cursed duet today: tuberculosis and HIV-coinfection. Presse Médicale. 2017;46:e23-39.

64. Bock P, Jennings K, Vermaak R, Cox H, Meintjes G, Fatti G, et al. Incidence of tuberculosis among HIV-positive individuals initiating antiretroviral treatment at higher CD4 counts in the HPTN 071 (PopART) trial in South Africa. J Acquir Immune Defic Syndr 1999. 2018;77:93-101.

65. Osler M, Hilderbrand K, Goemaere E, Ford N, Smith M, Meintjes G, et al. The continuing burden of advanced HIV disease over 10 years of increasing antiretroviral therapy coverage in South Africa. Clin Infect Dis Off Publ Infect Dis Soc Am. 2018;66 Suppl_2:S118-25.

66. Post FA, Szubert AJ, Prendergast AJ, Johnston V, Lyall H, Fitzgerald F, et al. Causes and timing of mortality and morbidity among late presenters starting antiretroviral therapy in the REALITY trial. Clin Infect Dis Off Publ Infect Dis Soc Am. 2018;66 Suppl_2:S132-9.

67. World Health Organization. Guidelines for managing advanced HIV disease and rapid initiation of antiretroviral therapy, July 2017; 2017.

68. Gualano G, Capone S, Matteelli A, Palmieri F. New antituberculosis drugs: from clinical trial to programmatic use. Infect Dis Rep. 2016;8:6569.

69. Mitnick CD, Rodriguez CA, Hatton ML, Brigden G, Cobelens F, Grobusch MP, et al. Programmatic management of drug-resistant tuberculosis: an updated research agenda. PLOS ONE. 2016;11:e0155968.

70. Zenner D, Beer N, Harris RJ, Lipman MC, Stagg HR, van der Werf MJ. Treatment of latent tuberculosis infection: an updated network meta-analysis. Ann Intern Med. 2017; 167:248-55

71. Matteelli A, Sulis G, Capone S, D’Ambrosio L, Migliori GB, Getahun H. Tuberculosis elimination and the challenge of latent tuberculosis. Presse Medicale Paris Fr 1983. 2017;46 Pt 2:e13-21.

72. Alsdurf $H$, Hill PC, Matteelli A, Getahun $H$, Menzies D. The cascade of care in diagnosis and treatment of latent tuberculosis infection: a systematic review and meta-analysis. Lancet Infect Dis. 2016;16:1269-78.

73. Njie GJ, Morris SB, Woodruff RY, Moro RN, Vernon AA, Borisov AS. Isoniazid-rifapentine for latent tuberculosis infection: a systematic review and meta-analysis. Am J Prev Med. 2018;55:244-52.

74. Cohen R, Lynch S, Bygrave H, Eggers E, Vlahakis N, Hilderbrand K, et al. Antiretroviral treatment outcomes from a nurse-driven, community-supported HIV/AIDS treatment programme in rural Lesotho: observational cohort assessment at two years. J Int AIDS Soc. 2009;12:23.

75. Nganda B, Wang'ombe J, Floyd K, Kangangi J. Cost and cost-effectiveness of increased community and primary care facility involvement in tuberculosis care in Machakos District, Kenya. Int J Tuberc Lung Dis Off J Int Union Tuberc Lung Dis. 2003; 7 Suppl.1:S14-20.

76. Floyd K, Skeva J, Nyirenda T, Gausi F, Salaniponi F. Cost and cost-effectiveness of increased community and primary care facility involvement in tuberculosis care in Lilongwe District, Malawi. Int J Tuberc Lung Dis Off J Int Union Tuberc Lung Dis. 2003;7 Suppl.1:S29-37.

77. Sinanovic E, Floyd K, Dudley L, Azevedo V, Grant R, Maher D. Cost and cost-effectiveness of community-based care for tuberculosis in Cape Town, South Africa. Int J Tuberc Lung Dis Off J Int Union Tuberc Lung Dis. 2003;7 Suppl.1:S56-62.

78. Pathmanathan I, Pasipamire M, Pals S, Dokubo EK, Preko P, Ao T, et al. High uptake of antiretroviral therapy among HIV-positive TB patients receiving co-located services in Swaziland. PLOS ONE. 2018;13:e0196831.

79. Ferroussier O, Dlodlo RA, Capo-Chichi D, Boillot F, Gninafon M, Trébucq A, et al. Results of rapid and successful integration of HIV diagnosis and care into tuberculosis services in Benin. Int J Tuberc Lung Dis Off J Int Union Tuberc Lung Dis. 2013:17:1405-10

80. Ferroussier O, Dlodlo RA, Capo-Chichi D, Boillot F, Gninafon M, Trébucq A, et al. Integrating HIV testing and care into tuberculosis services in Benin: programmatic aspects. Int J Tuberc Lung Dis Off J Int Union Tuberc Lung Dis. 2013:17:1402-4

81. MSF MF, Brussels, 2016. Out of Focus: How millions of people in West and Central Africa are being left out of the global HIV response.

82. Turnbull ER, Kancheya NG, Harris JB, Topp SM, Henostroza G, Reid SE. A model of tuberculosis screening for pregnant women in resource-limited settings using Xpert MTB/RIF. J Pregnancy. 2012;2012:565049-55.

83. World Health Organization. The end TB strategy. Geneva, Switzerland: WHO 2015. 